DOI: 10.22616/REEP.2019.026

\title{
Factors Affecting the Result of a Secondary School Math Exam
}

\author{
Aleksandrs Vorobjovs Mg. Ed. \\ University of Latvia, Latvia \\ aleksandrs.vorobjovs@gmail.com
}

\begin{abstract}
The results of the Latvian students in the mathematics exam are below expectations from year to year at an average score of $37 \%$ over past three years being the worst result among all centralized exams (CE) in Latvia. Despite these worrying statistics, only three researches were published in the last 10 years by responsible institutions, mostly covering bad news. This is why the aim of this article is to encourage scientific discussion on undisputed unsatisfactory results in math, to determine factors with the greatest influence on the results of a secondary school math exam and to discuss potential improvements in preparing for the exam. The study was held in Marupe Secondary School in suburb of Riga, Latvia. A huge amount of data was collected about 53 respondents over their three years of studying in high school classes and after passing the exam. All obtained data were analyzed in search of correlation between exam score and all kinds of factors. Factors with the highest impact turned out to be results in physics, Latvian and biology, problem solving and modelling skills, proactively asking for help if a student did not understand the concept. It is also useful to learn factors that have a negative correlation with exam results, for example, regular homework assignment led to significantly lower result in the exam. During this research it proved to be wrong to consider that solving past exams is a factor with positive interdependence with exam score, because no correlation was found. It is significant to discuss these and all kind of other data-based findings on why student results in mathematics in Latvia are this low to prevent relying on stereotypes reproduced for years and to keep on searching for the best approaches of teaching and learning mathematics.
\end{abstract}

Keywords: school education, mathematics, exam results.

\section{Introduction}

Results in centralized exams (CE) are essential for most high school graduates, since $91 \%$ of graduates choose to study at universities in Latvia, where the most common admission criterion is the CE result. Only $9 \%$ of graduates choose to study abroad (Dedze et al., 2011), so in their case CE results are not determinative - foreign universities mostly select students based on their own entrance exam.

Exam results in percentage form represent the correct answers in points relative to the maximum possible score. If you compare average $\mathrm{CE}$ results in different subjects, each year result in mathematics is either the lowest or with rare exceptions the second from the bottom (Figure 1). Based on the data provided by the State Education Content Centre Latvian students demonstrate almost the same low result in CE in mathematics every year. For example, in 2016 it was $36.2 \%$, in $201734.9 \%$ and last year $38.8 \%$ (VISC, 2018). Results in mathematics are quite mediocre also in gymnasiums, for instance, last year just $42.3 \%$.

Despite the fact that student results in mathematics when graduation high schools are low, this issue earns attention just for some days after the results are revealed. This topic is then mostly covered by mass media with articles quoting students who describe the exam as too complicated and those responsible for its content saying CE meets the standard requirements. Researchers pay little attention if any to this problem. In 2016 the state institution responsible for preparing exam papers published a methodical material for teachers about the results and performance of students in mathematics CE. Authors of this publication conclude that student's results in past years show that overall students have not attained sufficient level in the standard mathematical skills like applying algorithms that every mathematics teacher is trying to develop and train. This material also questions the level of understanding of the concepts and refers to some common knowledge like "pupils have different mathematical learning experience". At the same time, this piece of work lacks expertise and practical advices (Cakane et al., 2016). Authors of this material also doubt students' reading skills and critical thinking, which could be an affecting factor and could be not, since students gain almost double the percentage in biology and chemistry (Figure 1), where both mentioned skills are important as well. 
Before this methodical work, a similar work has been published five years earlier (Vilcins, 2011). Its conclusions were even more general, the most critical of them being "The average achievements of pupils in individual tasks cause reflections on the acquisition of the skills to be tested during the study process". The third source to question results in mathematics CE is dated back in 2009, when Latvian Ministry of Education and Science financed analysis on preparation for the transition to a single Latvian language exam. Two pages of this report were dedicated to mathematics exam.

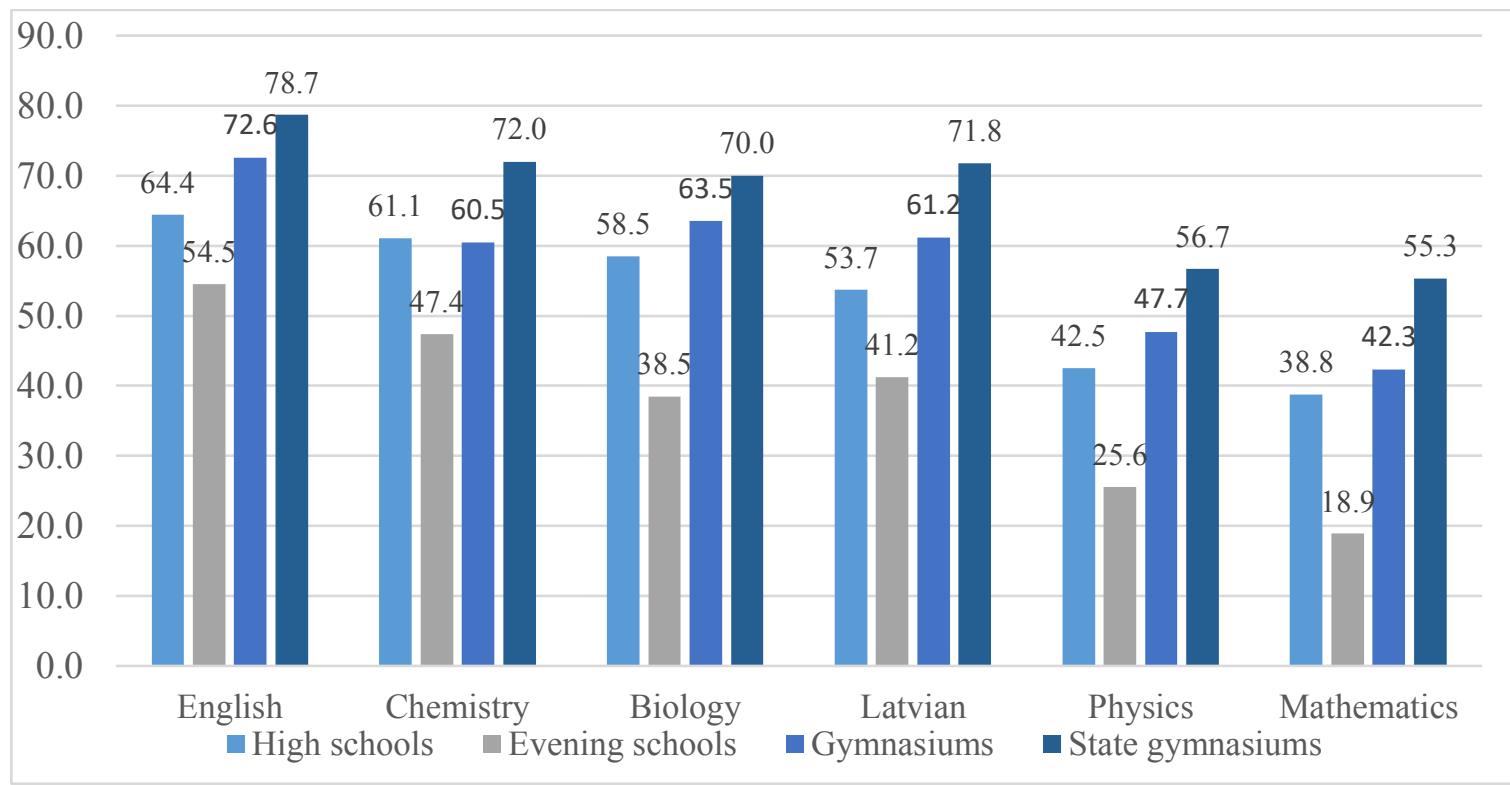

Figure 1. Centralized exam results by school type in school year 2017/2018 (VISC, 2018).

Authors found out those students from minority schools showed significantly better results than students who studied in Latvian. For example, in 2009 the difference was, respectively, $46.6 \%$ compared to $34.5 \%$ (Centralizeto ekamenu pedejo..., 2009). Despite being called "analysis", no explanation or at least hypothesis on why is to so is given in this publication. Vast majority of publications and research on students' success in mathematics focus on OECD PISA test results of 15-year-old students, so the conclusions of these materials are not always applicable for high school graduates, who are normally 18 or 19 at the time of exam session. However, a recent survey of first-year students shows that mathematical competences acquired in secondary schools are mediocre. For example, only 1 in 6 students self-reflected to be able to think mathematically and just $10 \%$ of secondary school graduates got reasoning skills during mathematics course (Zeidmane, Rubina, 2018). Based on this and other surprising evidence, researchers conclude secondary school graduates are not ready for studies at the university (Zeidmane, Rubina, 2017). Riga Technical University is even more outright: first year students are given elementary mathematics tests, and on average $45 \%$ of students fail on this test (Volodko, Cernajeva, 2015).

The aim of the article is to start a scientific discussion on this case, to determine factors with the greatest influence on the results of a secondary school math exam and to discuss potential improvements in preparing for the exam, which influences ability of secondary school graduates to successfully continue studying at higher level.

\section{Methodology}

To identify the factors affecting the result of a secondary school math exam, other researches in global and Latvian literature have been studied. Pedagogical experiment was held in a relatively huge Marupe Secondary School near Riga with over 1200 students, approximately 230 of them being high school students who mostly choose to master mathematics or commercial science and economics in depth.

This is a case study carried out from 2014 to 2018. Potential weakness of this study that threatens generalization of its results is a relatively small number of respondents: 53 graduation year students. Of these respondents 25 mastered mathematics and 28 - commercial science. On the other hand, it involves data about students during three years of studies in high school, including:

- test results; 
- absence statistics;

- standardized well-being and attitude survey adapted from "Teach for All" every semester;

- since the researcher was also a mathematics teacher for all of these 53 students, also all kinds of observations from the lessons and after-lesson activities, such as learning styles, behavior in a new situation, stress persistence, overall attitude to learning;

- test on mathematical competencies;

- individual centralized exam results showing percentage score of each student in all three parts of the exam;

- before and after-exam questionnaire as a reflection on the performance preparing for the exam and during the exam.

Research questions are: 1) what factors have the greatest influence on the results of a secondary school math exam; 2) what potential improvements can be concluded from these factors?

\section{Results and Discussion}

Mathematics CE result correlates quite strong with the results in other subjects (Table 1). This means mathematics cannot be seen separately, this is why a student may expect a considerably good result in mathematics only in case of having some effort in all subjects.

Table 1

The correlation coefficient of the results of CE of other subjects with the result in mathematics

\begin{tabular}{|c|c|c|}
\hline Subject & $\mathbf{2 0 1 7}$ & $\mathbf{2 0 1 8}$ \\
\hline Physics & 0.90 & 0.66 \\
\hline Biology & 0.85 & 0.55 \\
\hline Latvian & 0.77 & 0.57 \\
\hline English & 0.73 & 0.44 \\
\hline
\end{tabular}

Of all correlations obtained during this research, the result of the mathematics CE correlated the most with the result in physics. Last year the correlation coefficient between mathematics and physics CE result was 0.66 , in 2017 it was even more impressive at 0.90 , which is almost a linear function. This means you can almost certainly predict the result of a student in mathematics given the percentage of this student in physics CE (Figure 2). Of course, one must keep in mind that the math exam is compulsory, but physics is optional, but still each year at least 10 students choose to pass the physics exam.

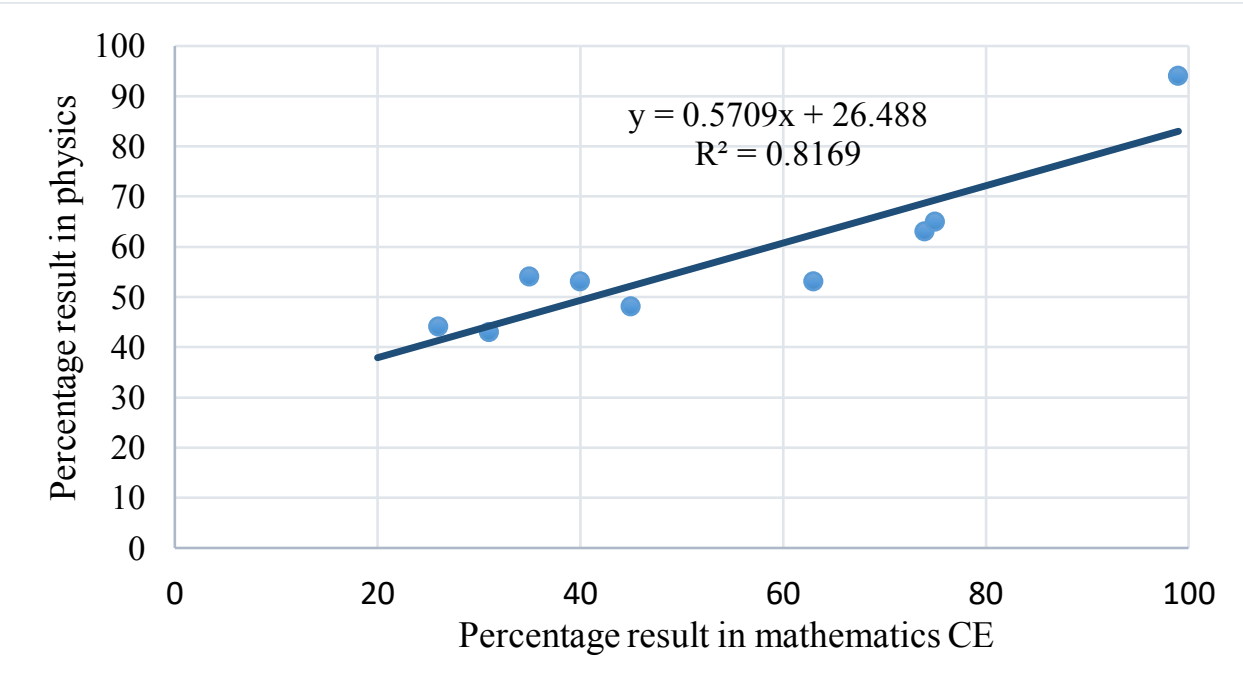

Figure 2. Correlation diagram between mathematics and physics $\mathrm{CE}$ results.

It is interesting that a similar study held from 2009 to 2012 in Nigeria showed very weak or even no correlation between mathematics and physics (Abdurrahman, Madugu, 2014). The strongest correlation during this study was 0.38 in 2009 , which is considered to be a moderately weak, and the weakest correlation was 0.02 in 2011 which indicates no relation between success in these two subjects at all. 
Meanwhile most studies in the field of interrelation between mathematics and physics show evidence of close relation. For example, researching mutual influence between mathematics and physics all along their history, author from Greece comes to a conclusion that "it is impossible to deeply understand either mathematics or physics without being sufficiently aware of their interconnections" (Tzanakis, 2016).

The second strongest correlation is between mathematics and biology (0.85 in 2017, which is a strong relation) and the third - between mathematics and Latvian. This can be explained by similarity of tested skills in all four exams just mentioned: mathematics, physics, biology and Latvian. Both students in a questionnaire and researchers all around the world are unanimous - these exams more than others require extensive use of reading skills, critical thinking, problem solving and analysis. Most authors explain it with "the rich historical relation between physics, mathematics, and the biological sciences" extending over several centuries (Mackey, Santillan, 2005). Other authors accentuate that teaching biology and physics has changed a lot lately, expanding to several fields predominantly explored by mathematicians in the past, for example, statistics in experimental design; pattern seeking; models in evolution, ecology, and epidemiology; applications of complex numbers in modelling any vector quantities and so on (May, 2004). Since "biology in general has finally embraced mathematics as an indispensable partner, and that biology enriches and will continue to enrich mathematics" (Hofmeyr, 2017).

The close relation between scores in native or foreign languages and mathematics is a globally wellcovered phenomenon. You may find examples of research and proof all around the world (Henry, Nistor, Baltes, 2014; Oh, 2010; Rambely et al., 2013). Researchers from Malaysia found out that students in a lower English proficiency group showed a negative relationship with mathematics achievement.

Before the exam, students took part in a test on mathematical competencies. Of all components of mathematical competence, the result in mathematics CE correlated the most with problem solving skill. This skill was measured by several tasks (Figure 3), which were selected based on an understanding that problem solving is a set of skills, including ability to formulate and solve various types of mathematical tasks: open type and with one correct answer; abstract and real-world problems (Lester et al., 1994).

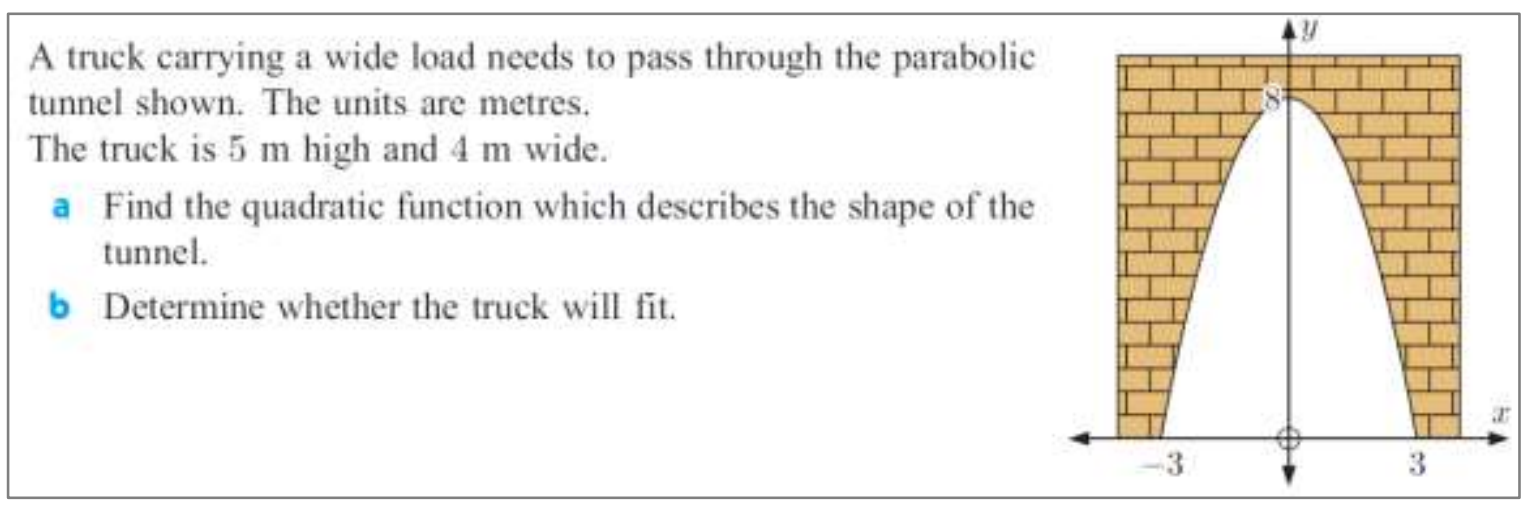

Figure 3. A task from questionnaire on mathematical competence (Martin et al., 2012).

Correlation between overall score in mathematics CE and score in problem solving tasks is 0.59 - not too strong, but above average. This skill is less related to results in Part 1 where students are asked to solve one step problems on basic knowledge and Part 2 consisting of applying knowledge in standard situations ( 0.51 and 0.50 respectively). Meanwhile correlation with Part 3 is stronger: 0.64. Part 3 examined use of knowledge in non-standard situations. Usually it consists of three tasks where students should prove, model or explore all cases.

Second most related component is modelling ( $r=0.53$ to overall score). Modelling correlates the most with Part 1 of CE since $60 \%$ of this part consist of multiple-choice questions. Reflecting on strategies of taking Part 1, students revealed they mostly used exclusion method and after that checking possible options by substituting them into the equation, solving the problem backwards from the answer or applying other modelling approaches.

Other components of mathematical competence correlated with CE score significantly less with one exception - mathematical intuition has a correlation coefficient of 0.48 with Part 2 of mathematics exam. Meanwhile such personal traits as persistence and curiosity even had although small but negative 
coefficient with Part 1 of around -0.3. It means that students who proved to be more persistent and curious in a questionnaire showed slightly worse results in one-step tasks.

Students also answered a lengthy questionnaire covering various aspects of student's everyday lives including questions about solving past exams, frequency of doing homework, dealing with mathematics problems, having a driver's license and many other. Only some of these aspects had a statistically significant impact on CE result.

The most pronounced effect was caused by the way students responded if they did not understand something in the learning process. All students with Top-10 scores, asked, what did they do if after a second explanation the concept was still not clear for them, replied that they continued to understand the idea. For example, "I talk to a teacher and did not stop until I realized how it works", "I went through it again by myself" or "I asked for a clarification again and if I still did not understand I continued to think about it until I understood". Students with the lowest results answered the same question saying they would usually ignore the question and hope it would not appear on the test or exam or try to find the answer in the Internet not to leave blank spaces in the worksheet. Students with overall percentage of $33 \%$ ( $14 \%$ below average) answered as follows: "Often I did not ask, because I was ashamed that I did not understand."

Second by the impact was the question "How many percent of the exam time did you use while taking the exam?" Students who used all or almost all time intended for writing had better scores with correlation coefficient of 0.38 . This factor had a relatively smaller influence on Part 1 and higher, very close influence on Part 2 and Part 3.

Significantly, the result was also affected also by the driving experience of a student. Those students, who drove car on every-day basis, had a better result in Part 3 with correlation coefficient of 0.33 which is moderately low interdependence but unexpected enough to mention it.

All the other correlations in the questionnaire were below 0.3 , most of them being around 0 which indicates no correlation. Among them, the most surprising can be mentioned: there was a precisely 0.0 correlation between CE result and the number of past exams student solved preparing for the exam. There is a persistent belief that solving past exams guarantee some advantage in the score but it did not appear to be so during this research.

Before the research, it was hard to predict that doing homework has a medium high negative correlation with CE result. Student who regularly did homework had a lower result in Part 1 with a correlation coefficient of -0.56 . Homework regularity had a little, but also negative impact on Part 2 scores and almost no effect on Part 3.

Respondents of this research had a quite different learning experience during the high school years. Researcher had an opportunity to teach 25 of them for all three years and 28 - for the last year before exam. The first group learned mathematics in depth and the second was a commercial science class. Based on standardized well-being and attitude survey in the end of each semester and everyday observations of student learning strategies, students from the mathematics group were more focused on work, more independent in learning and persistent. The commercial science group students highlighted as benefits opportunity to have discussions on this moment important topics in Latvia, to learn in an informal environment and similar factors not directly related to learning. The average result of the first group was $58 \%$ and the second one $-36 \%$. For sure, you could expect mathematics group having better results, but the result of commercial science group was noticeably lower than in the same group in previous years. To be more specific, it was down by $11 \%$. Possibly, it is caused by low expectations of second group students.

Student attendance data indicate different influence of absence on CE results for students with high, medium and low results. Students with high overall score had a slightly better result in CE if the amount of absence day was higher (correlation coefficient 0.27 ). This could be explained by the fact that this group of students are absent usually because of taking part in Olympiads.

On the contrary students with lowest results in CE who did not attend mathematics lessons more often than other students from this group had a lower result in exam, still the coefficient of interdependence here was not too high: -0.42 . The most surprising fact about absence is that students with average results in the CE (between $34 \%$ and $43 \%$ overall score) did have a significantly lower result in mathematics if they missed some classes. Even though this result could be expected, the unforeseen fact about it is 
the correlation coefficient of -0.68 , which indicates quite high interdependence (Figure 4$)$. This finding proves that students with lower and especially medium results should mind missing a day at school.

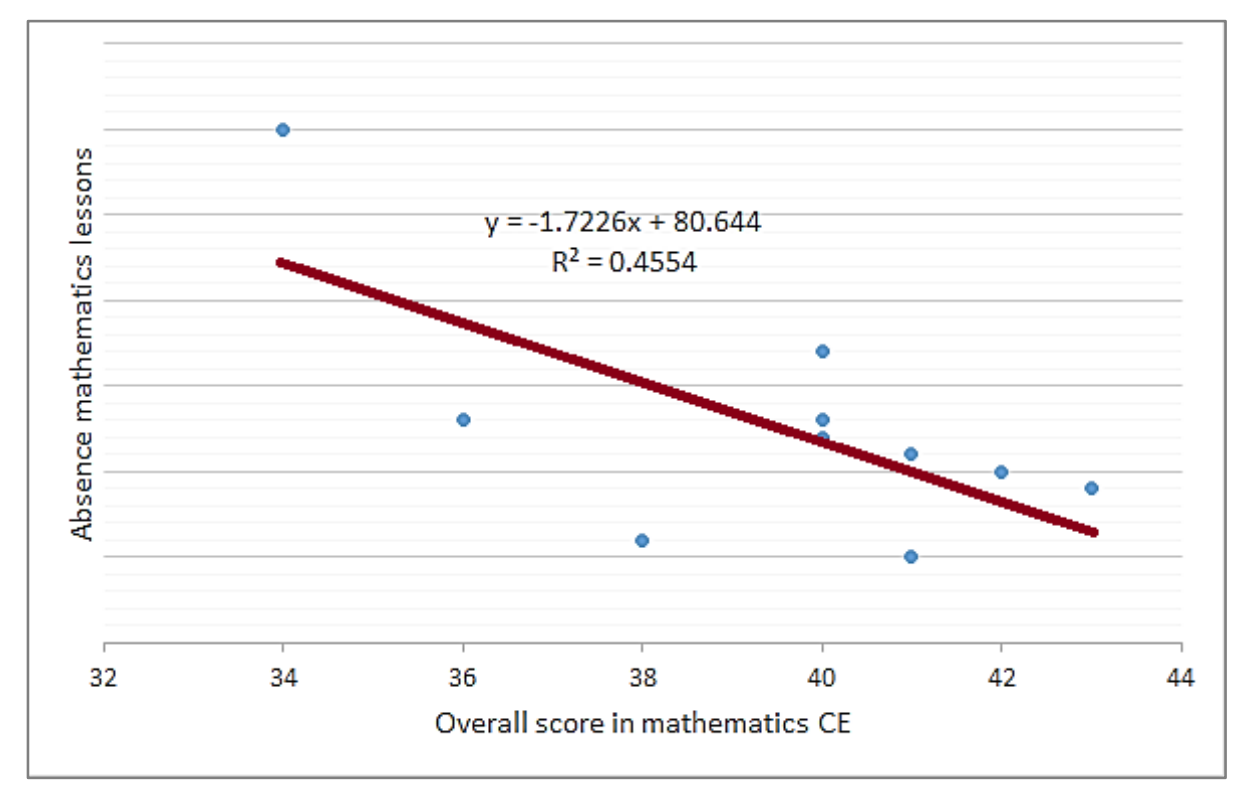

Figure 4. Correlation between CE result in mathematics and not attended mathematics lessons.

The last three weeks before the $\mathrm{CE}$ are meant for individual consultations, and the frequency of attending these consultations has once again a great impact on the exam result. All of 10 students with the highest scores in exam attended at least one consultation and 6 out of 10 attended all consultations. Students with the best two results spent vastly more time for individual consultations than it was required according to a plan. Meanwhile among students with 10 lowest results none of them attended all consultations, 1 student attended almost all consultations, 2 - some and 7 did not attend any.

\section{Conclusions}

Factor with the biggest impact on mathematics results appeared to be results in exact sciences (physics and biology) and languages, with a higher interdependence with native language and a bit smaller - with foreign languages. This hypothesis split into parts can be found in several researches. This conclusion should motivate teachers of mentioned subject cooperate more on interdisciplinary project to gain the best outcome for all involved subjects. Next strongest impact on exam result are problem solving and modelling skills. Researches in Latvia show that both concepts are relatively new and obscure for teachers. As for what student might do to ensure a better result, to-do list is as follows: proactively ask for help if something is not clear; attend as much mathematics lessons and consultations as it is possible; expect a higher result than your current level; be focused, patient, curious and not too informal while in class.

\section{Bibliography}

1. Abdurrahman M.S., Madugu A. (2014). Interrelationship Between Students' Performance in Mathematics and Physics in Senior Secondary Schools of Birnin-Kebbi Local Government Area of Kebbi State. International Journal of Scientific and Engineering Research, 5(11), 1494-1507. Retrieved from https://www.ijser.org/researchpaper/interrelationship-between-studentsperformance.pdf

2. Cakane L., France I., Kalis M., Ancupans A. (2016). Matematikas centralizetais eksamens 2015./2016.m.g.; skolenu rezultatu un snieguma analize (Centralized Mathematics Examination 2015/2016; Analysis of Student Results and Performance). Riga: VISC. Retrieved from https://visc.gov.lv/vispizglitiba/eksameni/dokumenti/metmat/2015_2016_ce_matemat_analize.p df (in Latvian)

3. Centralizeto eksamenu pedejo tris gadu rezultatu analize un sagatavotibas parejai uz vienotu latviesu valodas eksamenu 2012. gada izpete (Analysis of the Results of Centralized Examinations Over the Last Three Years and Preparation for the Transition to a Single Latvian Language Exam 
in 2012). (2009). Riga: Baltic Institute of Social Sciences. Retrieved from http://www.izm.gov.lv/images/statistika/petijumi/08.pdf (in Latvian)

4. Dedze I., Strode I., Rotkovska Z., Kovaleva N. (2011). Social and Economic Conditions of Student Life in Europe. National Profile of Latvia. Riga: University of Latvia, SKDS. Retrieved from https://dspace.lu.lv/dspace/bitstream/handle/7/1397/EUROSTUDENT IV Data Latvia F.pdf

5. Henry D., Nistor N., Baltes B. (2014). Examining the Relationship Between Math Scores and English Language Proficiency. Journal of Educational Research and Practice, 4(1), 11-29. Retrieved from https://files.eric.ed.gov/fulltext/EJ1118452.pdf

6. Hofmeyr J.H.S. (2017). Mathematics and biology. South African Journal of Science, 113(3/4). Retrieved from https://www.sajs.co.za/article/view/3628/

7. Lester F.K.Jr., Masingila J.O., Mau S.T., Lambdin D.V., dos Santon V.M., Raymond A.M. (1994). Learning how to teach via problem solving. In D. Aichele, A. Coxford (Eds.) Professional Development for Teachers of Mathematics, 152-166. Reston, Virginia: NCTM.

8. Mackey M.C., Santillan M. (2005). Mathematics, Biology, and Physics: Interactions and Interdependence. Notices of The AMS, 52(8), 832-840. Retrieved from https://www.ams.org/notices/200508/fea-mackey.pdf

9. Martin D., Haese R., Haese S., Haese M., Humphries M. (2012). Mathematics for the International Student. Mathematics HL (Core). ( $3^{\text {rd }}$ ed.). Adelaide: Haese Mathematics.

10. May R.M. (2004). Uses and Abuses of Mathematics in Biology. Science, 303(5659), 790-793. Retrieved from http://science.sciencemag.org/content/303/5659/790

11. Oh H. (2010). A Study on the Relation Between Mathematics and Foreign Language. The Korean Journal of Mathematics, 18(4), 409-424. Retrieved from

http://citeseerx.ist.psu.edu/viewdoc/download?doi=10.1.1.1004.4126\&rep=rep1\&type=pdf

12. Rambely A., Majid N., Ahmad R.R., Jaaman S.H. (2013). The Relationship of English Proficiency and Mathematics Achievement. Conference: Recent Advances in Educational Technologies. (EET'13), 139-145. Retrieved from

https://www.researchgate.net/publication/279181382_The_Relationship_of_English_Proficiency and_Mathematics_Achievement

13. Tzanakis C. (2016) Mathematics and Physics: an Innermost Relationship. Didactical Implications for Their Teaching and Learning. History and Pedagogy of Mathematics, Jul 2016, Montpellier, France. Retrieved from https://hal.archives-ouvertes.fr/hal-01349231/document

14. Vilcins J. (2011). Matematikas centralizeta eksamena 2010./2011.m.g. rezultatu un skolenu snieguma analize (Centralized Mathematics Examination 2010/2011. Results and Student Performance Analysis). Riga: VISC. Retrieved from

https://visc.gov.lv/vispizglitiba/eksameni/dokumenti/metmat/20120126_mat_eks_analize.pdf (in Latvian)

15. VISC. (2018). Valsts pārbaudes darbi 2017./2018. m.g. Norises statistika un rezultatu raksturojums. (State Examination in School Year 2017/2018. Statistics of progress and characteristics of the results). Riga: VISC. Retrieved from

https://visc.gov.lv/vispizglitiba/eksameni/statistika/2018/ (in Latvian)

16. Volodko I., Cernajeva S. (2015). Improving Knowledge of Elementary Mathematics - the Way to Better Studying of Higher Mathematics. In V. Dislere (Ed.), The Proceedings of the International Scientific Conference Rural Environment. Education. Personality (REEP), 8. Jelgava: LLU TF, 401-406. Retrieved from http://lufb.llu.lv/conference/REEP/2015/Latvia-Univ-Agricult-REEP2015proceedings.pdf

17. Zeidmane A., Rubina T. (2017). Causes of Failures in Mathematics by Engineering Students at Latvia University of Agriculture. In V. Dislere (Ed.), The Proceedings of the International Scientific Conference Rural Environment. Education. Personality (REEP), 10. Jelgava: LLU TF, 220-227. Retrieved from http://lufb.llu.lv/conference/REEP/2017/Latvia-Univ-Agricult-REEP2017 proceedings.pdf

18. Zeidmane A., Rubina T. (2018). The Contribution of Mathematics to the Engineering Education in the Students' Assessment. In V. Dislere (Ed.), The Proceedings of the International Scientific Conference Rural Environment. Education. Personality (REEP), 11. Jelgava: LLU TF, 244-250. Retrieved from http://llufb.1lu.lv/conference/REEP/2018/Latvia_REEP_2018_proceedings_ISSN2255808X.pdf 